\title{
Prevalence of methicillin resistant Staphylococcus aureus in selected seafood markets and aquaculture farms in Kerala, south-west coast of India
}

\author{
V. MURUGADAS, TOMS C. JOSEPH, K. RESHMI AND K. V. LALITHA \\ ICAR-Central Institute of Fisheries Technology, Willingdon Island, Kochi - 682 029, Kerala, India \\ e-mail:murugadascift81@gmail.com
}

\begin{abstract}
A study was carried out to understand the prevalence of methicillin-resistant Staphylococcus aureus (MRSA) in selected seafood commodities, market environment as well as in aquaculture farms in Kerala, along the south-west coast of India. Two hundred and thirty three samples comprising finfish, crustaceans, molluscs and fishery environmental samples from markets as well as aquaculture farms were collected and screened for the presence of MRSA. The $S$. aureus isolates obtained from the samples were checked for resistance to methicillin, oxacillin and cefoxitin by antimicrobial sensitivity test and further confirmed by oxacillin agar screening method. A multiplex PCR was employed targeting mecA, nuc and $16 s \mathrm{rDNA}$ genes to differentiate $S$. aureus and MRSA from other staphylococci. It was found that $13.4 \%$ of the samples harboured MRSA while the overall prevalence of $S$. aureus was found to be $36.5 \%$. This study has clearly indicated high prevalence of methicillin resistant $S$. aureus strains in the seafood as well as in environmental samples from seafood markets and aquaculture farms in Kerala. The prevalence of methicillin resistant strains of staphylococci in fish indicates high risk associated with fish handlers and fish farmers.
\end{abstract}

Keywords: mecA gene, Methicillin-resistant Staphylococcus aureus, MRSA, Prevalence, Seafood

Staphylococcus aureus, a well known pathogen of hospital acquired infection and food poisoning (Khan et al., 2015), is a commensal organism of skin and mucous membrane of different species of animals as well as human beings and is not generally considered as the normal microflora of fish (Huss, 1988; Mc Carthy et al., 2012). Remarkably, 20\% of individuals are persistently and 30\% are transiently colonised with $S$. aureus in the nose (Liu, 2009). When the methicillin sensitive $S$. aureus (MSSA) acquires the genes responsible for methicillin resistance, the organism causes higher morbidity and mortality in humans with prolonged period of hospitalisation and are called as methicillin resistant $S$. aureus (MRSA) (Datta and Huang, 2008). There are a few reports on the prevalence of $S$. aureus in fish and fishery products from local retail markets and imported samples (Ayulo et al., 1994; Simon and Sanjeev, 2007; Saito et al., 2011; Bujjamma and Padmavathi, 2015; Obaidat et al., 2015). MRSA and methicillin resistant coagulase negative staphylococci (MR-CoNS) are recognised as zoonotic multidrug resistant pathogens causing hospital and community acquired infections in humans as well as infections in animals (Dahms et al., 2014). Resistance to methicillin is determined by mecA, encoded for low affinity penicillin binding protein PBP2A (Beck et al., 1986). Non-mecA mediated methicillin resistance in $S$. aureus may be due to excess production of beta-lactamase resulting in low level resistance to oxacillin called as borderline oxacillin resistant Staphylococcus aureus (BORSA) (Maalej et al., 2012) or due to presence of a novel mecA gene homologue ( $m e c A$ LGA251 or $m e c C$ ) causing resistance to beta-lactam antibiotics (Garcia-Alvarez et al., 2011). The prevalence of MRSA in fish was first reported from Malaysia in farmed tilapia (Atyah et al., 2010). Visnuvinayagam et al. (2015,) and Kumar et al. (2016) reported on presence of MRSA from Indian seafood. The present study was conducted to investigate the prevalence of methicillin resistant $S$. aureus in seafood markets and aquaculture environments from selected locations along the southwest coast of India.

A total of 233 samples comprising finfishes $(n=137)$, crustaceans $(n=31)$, molluscs $(n=26)$ and environmental samples $(n=39)$ were collected during July 2012 to April 2015 from selected retail markets and aquaculture farms covering three districts along the south-west coast of India viz., Ernakulam, Kottayam and Alappuzha. Environmental samples comprised water, swabs and ice from retail markets as well as water and sediment from aquaculture farms. Samples were transported to the laboratory in chilled condition and processed as per the standard protocol of United States Food and Drugs Administration (USFDA) for isolation of $S$. aureus in preprocessed food (Bennett and Lancette, 2001), with slight modifications. Ten gram of each sample was transferred to Tryptic soy 
broth (TSB) (BD BBL \& Difco, USA) supplemented with $\mathrm{NaCl}(10 \%)$ and sodium pyruvate $(1 \%)$ and incubated at $35^{\circ} \mathrm{C}$ overnight. Serially diluted, overnight enriched sample $(0.5 \mathrm{ml}$ each $)$ was inoculated by spread plating onto preset Baird-Parker agar base (BPA) (BD Difco, USA) supplemented with egg yolk potassium tellurite enrichment (BD BBL \& Difco, USA). The plates were incubated at $35^{\circ} \mathrm{C}$ for 36 to $48 \mathrm{~h}$. Additionally the enriched samples were plated onto BD Chromagar MRSA II (BD BBL \& Difco, USA) and Oxacillin resistance agar screen base supplemented with ORSAB supplement (Oxoid, UK). The characteristic convex shiny black colonies surrounded by narrow white margin and clear zone from BPA plates; mauve colony on BD chromagar II; deep blue colony from ORSAB were regarded as presumptive MRSA. These suspected colonies were confirmed as $S$. aureus by biochemical tests (Bennett and Lancette, 2001) and the isolates were maintained in tryptic soy agar slants supplemented with $6 \% \mathrm{NaCl}$.

The isolates confirmed as $S$. aureus were subjected to standard antimicrobial susceptibility tests by disk diffusion assay (CLSI, 2012; 2014) with oxacillin $(1 \mu \mathrm{g})$, methicillin $(5 \mu \mathrm{g})$ and cefoxitin $(30 \mu \mathrm{g})$. Turbidity of overnight grown cultures in TSB were adjusted to 0.5 McFarland Unit and spread plated onto Mueller-Hinton agar (BD Difco, USA) and incubated at $35^{\circ} \mathrm{C}$ for 16 to $24 \mathrm{~h}$. The results of susceptibility testing were interpreted as per CLSI (2014).

The isolates which showed reduced susceptibility to either or both oxacillin $(1 \mu \mathrm{g})$ or methicillin $(5 \mu \mathrm{g})$ or cefoxitin $(30 \mu \mathrm{g})$ were confirmed phenotypically for methicillin resistance by oxacillin agar screening method [Mueller-Hinton agar + oxacillin $6 \mu \mathrm{g} \mathrm{ml}^{-1}$ (Sigma) + 4\% $\mathrm{NaCl}]$ as per CLSI $(2012 ; 2014)$. S. aureus ATCC 43300 and S. aureus ATCC 29213 were used as positive and negative control strains respectively in all the antimicrobial susceptibility testing and oxacillin resistance confirmation.

Rapid DNA extraction was performed with $1 \mathrm{ml}$ of overnight grown young culture in $500 \mu \mathrm{l}$ of $1 \mathrm{x}$ TE buffer (pH 8.0), heated at $99^{\circ} \mathrm{C}$ for $10 \mathrm{~min}$ and cooled rapidly to $-20^{\circ} \mathrm{C}$ until use. Multiplex PCR was performed as described by Zhang et al. (2004) in a Veriti Thermal Cycler (Thermofisher scientific, USA) with a $25 \mu 1$ of PCR reaction mixture containing $3 \mu \mathrm{l}$ of template DNA, 1x Taq buffer, $2.5 \mathrm{mM} \mathrm{MgCl}_{2}, 200 \mu \mathrm{M}$ dNTPs mix (Thermofisher scientific, USA), $0.12 \mu \mathrm{M}$ of each primers (Staph756F 5-AAC TCT GTT ATT AGG GAA GAA CA-3; Staph750R 5-CCA CCT TCC TCC GGT TTG TCA CC-3 for Staphylococcus genus-specific 16S rRNA; $m e c A$ F 5-GTA GAA ATG ACT GAA CGT CCG ATA A-3 and mecAR 5-CCA ATT CCA CAT TGT TTC GGT
CTA A-3 for methicillin resistance genes $m e c A$ ); $0.04 \mu \mathrm{M}$ of $n u c \mathrm{~F}$ 5-GCG ATT GAT GGT GAT ACG GTT-3 and nucR 5-AGC CAA GCC TTG ACG AAC TAA AGC-3 for thermonuclease gene $n u c ; 0.65 \mu$ of Taq polymerase $1 \mathrm{U} \mu \mathrm{l}^{-1}$ (EP0404, Thermofisher scientific, USA) and nuclease free water. The thermal cycling conditions used were as follows: Initial denaturation of $94^{\circ} \mathrm{C}$ for $5 \mathrm{~min}$, followed by 10 cycles of $94^{\circ} \mathrm{C}$ for $40 \mathrm{sec}, 58^{\circ} \mathrm{C}$ for 40 sec, and $72^{\circ} \mathrm{C}$ for $1 \mathrm{~min}$; followed by 25 cycles of $94^{\circ} \mathrm{C}$ for $1 \mathrm{~min}, 50^{\circ} \mathrm{C}$ for $1 \mathrm{~min}$, and $72^{\circ} \mathrm{C}$ for $2 \mathrm{~min}$; with a final extension step at $72^{\circ} \mathrm{C}$ for $10 \mathrm{~min}$. The amplified PCR products were stored at $4^{\circ} \mathrm{C}$ until further analysis. The amplicons size were determined by electrophoresis employing $2.5 \%$ agarose gel (Sigma) in 1xTAE buffer. The size of the amplicons were compared to the $50 \mathrm{bp}$ plus DNA molecular weight marker (Thermofisher scientific, USA) and documented in a gel documentation system.

The screening of seafood as well as seafood market/ aquaculture environment of coastal Kerala for MRSA revealed that out of the 233 samples, $13.4 \%$ samples carried MRSA. Moreover, it is pertinent to note that $36.5 \%$ of the $S$. aureus positive samples were found to harbour MRSA. The prevalence of MRSA in finfish, crustaceans, molluscs and in the environment were $13.8,9.3,12$ and $15.3 \%$ respectively. Out of the 31 positive samples harbouring MRSA, 64.5, 32.2 and $3.3 \%$ belonged to Ernakulam, Kottayam and Alappuzha districts respectively. Incidence of $S$. aureus and MRSA in different sample types are depicted in Fig. 1. The results from this study revealed a higher prevalence of MRSA in comparison to that of $5 \%$ MRSA reported in ready-to-eat raw fish samples from fish market by Hammad et al. (2012) in Japan. Costa et al. (2015) reported presence of MRSA in raw fish and processed fish in hospital kitchen at 30 and $15 \%$ of the samples respectively.

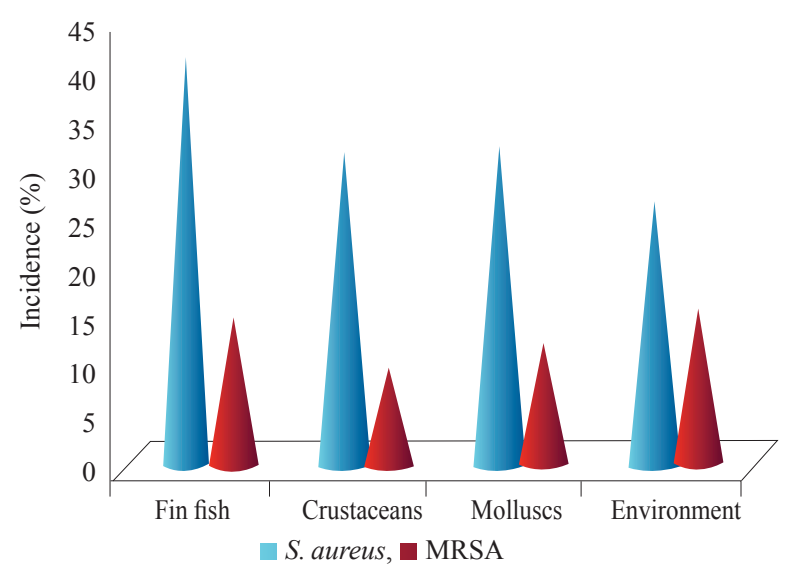

Fig. 1. Distribution of $S$. aureus and MRSA in seafood and fishery environment from south-west coast of India 
In the present study, based on the results of antimicrobial susceptibility and multiplex PCR, it was confirmed that the methicillin resistance of the isolates were mediated by mecA gene and not by non-mecA mediated resistance. All the MRSA strains gave amplicons of $310 \mathrm{bp}$ for mecA, $750 \mathrm{bp}$ for $16 \mathrm{~s}$ rDNA gene and 280 bp for nuc gene, whereas $S$. aureus produced only 16 s rDNA and nuc gene specific products (Fig. 2). Zhang et al. (2004) were able to differentiate $S$. aureus from MR-CoNS by multiplex PCR.

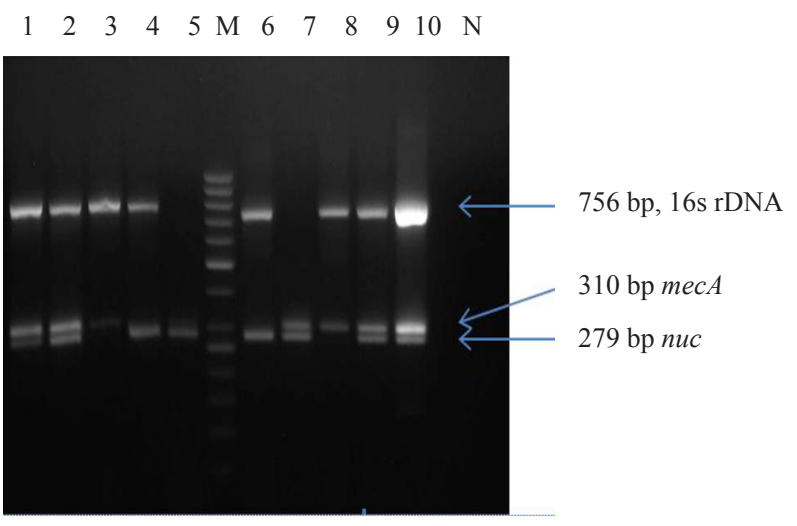

Fig. 2. Multiplex PCR for detection of MRSA

Lane1\&2: MRSA strains from samples; Lane 9\&10: MRSA positive controls ATCC 43300, ATCC33592;

Lane 3\&8: MR-CoNS sample strain; Lane4\&6: MSSA strain; Lane 5\&7: non staphylococci; Lane M: 50 bp molecular weight marker

Hammad et al. (2012) used BP agar with cefoxitin selective screening of MRSA/MR-CoNS; while Costa et al. (2015) used two enrichment procedures; primary enrichment in Mueller Hinton broth with $6.5 \%$ salt and secondary enrichment in phenol red mannitol salt broth with subsequent plating onto selective chromagar plate for detection of MRSA from raw and processed meat including fish. Atyah et al. (2010) reported prevalence of MRSA in cultured tilapia from Malaysia, where mannitol salt agar was used as screening medium. Weese (2010) reported that prevalence data may vary considerably according to methods for isolation, sample types and sample collection schemes employed. It is likely that protocols used for determining the prevalence of MRSA from fish samples may affect the prevalence rate and hence there is a need for harmonised protocol for detection of MRSA from food samples. Weese (2010) and Costa et al. (2015) have indicated that there is considerable increase in prevalence of MRSA in food animals and it is imperative that MRSA food poisoning may become more common in future. The study concludes that there is a prevalence of $13.4 \%$ methicillin resistant $S$. aureus in samples of fish, fishery products as well as market/aquaculture environments.
Hence there is a need to alert the fish farmers and fish handlers to adopt strict hygienic measures during harvest, handling and storage of fish. Further studies are required to trace the source of contamination by MRSA in seafood and fishery environment.

\section{Acknowledgements}

The authors are thankful to the Indian Council of Agricultural Research, New Delhi for funding the research and the Director, ICAR-CIFT, Kochi for the continuous support. Authors also express their gratitude to one and all from MFB Division of ICAR-CIFT.

\section{References}

Atyah, M. A. S., Zamri-Saad, M. and Siti-Zahrah, A. 2010. First report of methicillin-resistant Staphylococcus aureus from cage cultured tilapia (Oreochromis niloticus). Vet. Microbiol., 144: 502-504.

Ayulo, A. M., Machado, R. A. and Scussel, V. M. 1994. Enterotoxigenic Escherichia coli and Staphylococcus aureus in fish and seafood from the southern region of Brazil. Int. J. Food Microbiol., 24: 171-178.

Beck, W. D., Berger-Bachi, B. and Kayser, F. H. 1986. Additional DNA in methicillin resistant Staphylococcus aureus and molecular cloning of mec-specific DNA. J. Bacteriol., 165: 373-378.

Bennett, R. W. and Lancette, G. A. 2001. Staphylococcus aureus. In: Merker, R. L. (Ed.) Food and Drug Administration Bacteriological Analytical Manual, $8^{\text {th }}$ edn. (revision A), AOAC International, Gaithersburg, MD.

Bujjamma, P. and Padmavathi, P. 2015. Prevalence of Staphylococcus aureus in fish samples of local domestic fish market. Int. J. Curr. Microbiol. App. Sci., 4(5): 427-433.

CLSI 2012. Methods for dilution antimicrobial susceptibility tests for bacteria that grow aerobically: Approved Standard, $9^{\text {th }}$ edn. CLSI document M07-A9, vol. 32(2). Clinical and Laboratory Standards Institute, Wayne, PA, 68 pp.

CLSI 2014. Performance standards for antimicrobial susceptibility testing; Twenty-fourth informational supplement. CLSI document M100-S24, vol. 32, Clinical and Laboratory Standards Institute, Wayne, PA, 230 pp.

Costa, W. L. R., Ferreira, J. D. S., Carvalho, J. S., Cerqueira, E. S., Oliveira, L. C. and Almeida, R. C. C. 2015. Methicillin resistant Staphylococcus aureus in raw meats and prepared foods in public hospitals in Salvador, Bahia. Brazil. J. Food Sci., 80:147-150.

Dahms, C., Hubner, N. O., Wilke, F. and Kramer, A. 2014. Mini-review: Epidemiology and zoonotic potential of multiresistant bacteria and Clostridium difficile in livestock and food. GMS Hyg. Infect. Control, 9(3): 1-16.

Datta, R. and Huang, S. S. 2008. Risk of infection and death due to methicillin resistant Staphylococcus aureus in long-term carriers. Clin. Infect. Dis., 47(2): 176-181. 
Garcia-Alvarez, L., Holden, M. T., Lindsay, H., Webb, C. R., Brown, D. F., Curran, M. D., Walpole, E., Brooks, K., Pickard, D. J. and Teale, C. 2011. Methicillin resistant Staphylococcus aureus with a novel mecA homologue in human and bovine populations in the UK and Denmark: a descriptive study. Lancet Infect. Dis., 11: 595-603.

Hammad, A. M., Watanabe, W., Fujii, T. and Shimamoto, T. 2012. Occurrence and characteristics of methicillin resistant and susceptible Staphylococcus aureus and methicillin resistant coagulase negative staphylococci from Japanese retail ready-to-eat raw fish. Int. J. Food Microbiol., 156: $286-289$.

Huss, H. H. 1988. Fresh fish quality and quality changes. FAO Fisheries series, No. 29, FAO, Rome.

Khan, H. A., Ahmad, A. and Mehboob, R. 2015. Nosocomial infections and their control strategies. Asian Pac. J. Trop. Biomed., 5(7): 509-514.

Kumar, L. R. G., Kasim, A. K., Lekshmi, M., Nayak, B. B. and Kumar, S. 2016. Incidence of methicillin resistant staphylococci in fresh seafood. Adv. Microbiol., 6: 399-406.

Liu, G. U. 2009. Molecular Pathogenesis of Staphylococcus aureus. Infection Pediatr. Res., 65: 71-77.

Maalej, S. M., Rhimi, F. M. and Fines, M. 2012. Analysis of borderline oxacillin resistant Staphylococcus aureus (BORSA) strains isolated in Tunisia. J. Clin. Microbiol., 50: 3345-3348.

McCarthy, A. J., Breathnach, A. S. and Lindsay, J. A. 2012. Detection of mobile genetic element variation between colonising and infecting hospital-associated methicillin resistant Staphylococcus aureus isolates. J. Clin. Microbiol., 50: 1073-1075.

Obaidat. M. M., Salman, A,. E., Lafi, S. Q. Mohammad, O. M., Bani, S. A. E. and Shawkat, L. Q. 2015. Prevalence of Staphylococcus aureus in imported fish and correlations between antibiotic resistance and enterotoxigenicity. J. Food Prot., 11: 1930-2102.

Saito, E., Yoshida, N., Kawano, J., Shimizu, A. and Shizunobu, I. 2011. Isolation of Staphylococcus aureus from raw fish in relation to culture methods. J. Vet. Med. Sci., 73(3): 287-292.

Simon, S. S. and Sanjeev, S. 2007. Prevalence of enterotoxigenic Staphylococcus aureus in fishery products and fish processing factory workers. Food Control, 18: 1565-1568.

Visnuvinayagam, S., Joseph, T. C., Murugadas, V., Chakrabarti, R. and Lalitha, K. V. 2015. Status on methicillin resistant and multiple drug resistant Staphylococcus aureus in fishes of Cochin and Mumbai coast, India. J. Environ. Biol., 36: $571-575$.

Weese, J. S. 2010. Methicillin resistant Staphylococcus aureus in animals. ILAR J., 51(3): 233-244.

Zhang, K., Sparling, J., Chow, B. L., Elsayed, S., Hussain, Z. and Church, D. L. 2004. New quadriplex PCR assay for detection of methicillin and mupirocin resistance and simultaneous discrimination of Staphylococcus aureus from coagulase negative staphylococci. J. Clin. Microbiol., 42(11): 4947-4955. 